\title{
LA REGEPCIÓN DE LA LITERATURA ESPAÑOLA EN ALEMANIA EN EL SIGLO XVIII
}

En estudios sobre las relaciones literarias hispano-alemanas se considera el siglo XVIII, en general, como un siglo poco fecundo en comparación con la época anterior del Barroco, rica en intercambios culturales $^{1}$. No debe, pues, extrañar que en recientes estudios monográficos sobre la literatura alemana de la Ilustración no se mencione en absoluto la contribución de la literatura española. Sin embargo, al examinar más detenidamente los hechos se llega a la conclusión de que la recepción de la literatura española en el siglo XviII no sufre ningún tipo de interrupción, sino que, por el contrario, el comercio literario se intensifica mucho más en el nivel internacional. El proceso de recepción se hace más complicado y complejo debido tanto a la coexistencia de la literatura del Siglo de Oro con la moderna como a la interferencia de aquellas irradiaciones de la literatura española sobre Inglaterra y Francia que, con mayor o menor retraso, repercuten en Alemania, a través del filtro de la doble traducción o de la refundición y la versión. Surge un público literario nuevo y distinto: el lector burgués sustituye al lector humanista-cortesano; la crítica y las revistas literarias encauzan la recepción; la discusión teórica sienta nuevas preferencias dentro del estudio de la literatura española. En la geografía literaria se destacan activamente otras regiones de Alemania Central y del Norte que reemplazan a los países católicos, que hasta entonces eran los rectores. Las obras ascético-religiosas que ocupaban un lugar preponderante durante el Barroco van disminuyendo y, en su lugar, otros temas, formas y géneros literarios van ganando la predilección del nuevo público lector. La imagen de España tal como la fijan los relatos de viaje divulgados por Europa, la erudición y, no en último término, la representa-

1 Herbert O. Lyte, Spanish literature and Spain in some of the leading German magazines of the second half of the eighteenth century, Madison, 1932; GERHART HoffMEISTER, Spanien und Deutschland. Geschichte und Dokumentation der literarischen Beziehungen, Berlin, 1976; Nicolao Merker, Die Aufklärung in Deutschland, München, 1982; B. BeckerCantarino, "The rediscovery of Spain in enlightenment and romantic Germany", Monatshefte für den Deutschunterricht, 72 (1980), 121-134; Hermann Tiemann, Das spanische Schrifttum in Deutschland vor der Renaissance bis zur Romantik, Hamburg, 1936. 
ción puramente literaria de España, ejercen una influencia profunda sobre la difusión de las letras españolas.

Dos actitudes totalmente opuestas marcan, a principios del siglo, las concepciones eruditas acerca de la literatura española. Daniel Georg Morhof y Nikolaus Hieronymus Gundling son representantes de la reacción desfavorable, a pesar de no disponer de conocimientos exactos propios. Son víctimas de los atávicos prejuicios antiespañoles, difíciles de desarraigar en el mismo siglo de las luces, o bien deducen su crítica de manera teórico-determinista de las premisas de la fisiología humoral de la época. Morhof sostiene el concepto sobre el retraso cultural y la degeneración retórica de la literatura española². El profesor de filosofía, Gundling, enseña que los españoles son propensos a las ciencias sutiles y abstractas (derecho, filosofía escolástica, teología) ${ }^{3}$. Gundling y Morhof niegan rotundamente todo valor a la literatura española: los españoles no ponían "ningún afán en el arte" ni observaban laś reglas del mismo. Todavía en 1763 opina el suizo Johann G. Zimmermann: "La gran predilección de esa nación por lo extravagante trastorna la naturaleza, el modelo ejemplar de todo lo bello y noble"'4.

El hamburgués Christian Heinrich Postel representa el lado opuesto con su disertación De linguae Hispanicae difficultate, elegantia, et utilitate meletema $a^{5}$, en la que alaba de manera entusiasta a Cervantes, a Quevedo, al "summus Gracianus", al "magnus Góngora", a los escritores sobre teología y moral, la belleza del español frente a otros idiomas y su riqueza en refranes. Estos dos polos, Morhof-Gundling y Postel, ponen de manifiesto, asimismo, la tensión antagónica que dificulta en Alemania el lento.crecimiento de las nociones eruditas acerca del desarrollo de la-literatura española. Los estudios hispánicos de Lessing, cuyos méritos han sido justamente puestos de relieve ${ }^{6}$, suponían un nuevo y considerable impulso. Lessing intentó romper con la norma de la literatura clásica francesa, hasta entonces la única válida, y dio lugar a una nueva valoración de la literatura española (sobre todo de la comedia) desconocida en gran parte en la discusión teórica y por la crítica literaria. Desde entonces, entre los alemanes se percibe cada vez más fuertemente la queja de cuán poco sabemos sobre las letras en España. Al señalar Daniel Schiebeler la importancia de las revistas y de la crítica literaria como vehículos de difusión, su pensamiento se mueve dentro de la cate-

2 Unterricht von der Teutschen Sprache und Poesie, Lübeck-Frankfurt, $2^{a}$ ed., 1700, especialmente cap. III, "Von der Spanier Poeterey", pp. 193-205.

3 Otia, Frankfurt-Leipzig, 1706, p. 51.

4 Vom Nationalstolz. Über die Herkunft der Vorurteile gegenüber anderen Menschen und anderen Völkern, Zürich, 1980, p. 73.

5 Nova Literaria Maris Balthici et Septentrionis collecta, Lübeck, 1704, pp. 11-28.

6 Martin Franzbach, Lessings Huarte-Übersetzung (1752). Die Rezeption und Wirkungsgeschichte des "Examen de ingenios para las ciencias" (1575) in Deutschland, Hamburg, 1965. 
goría de la República literaria, pero no incluye a España ${ }^{7}$. Con motivo de la publicación del Journal Etranger, Melchior Grimm llamó también la atención en 1754, en su famosa Correspondencia, sobre "la importancia de reunir, con gusto y criterio, todo lo que las literaturas italiana, española, inglesa y alemana ofrecen de valioso y elegante"'8 para divulgarlo por Francia y Europa. En relación con la idea favorita de la "République des lettres" (y las no pocas sátiras al respecto en aquella época), es también significativa la versión del sueño burlesco-alegórico de Diego Saavedra Fajardo, Die Gelehrte Republic (1748), por sus juicios no sólo graciosos, sino, en parte, agudos y positivos acerca de la poesía, aunque, claro está, desde la perspectiva de principios del siglo XVII ${ }^{9}$.

Es, ante todo, la traducción Geschichte der spanischen Gelehrsamkeit de la obra de Luis José Velázquez, publicada en Göttingen por Johann Andreas Dieze en 1769 con múltiples anotaciones, la que hizo que se ampliaran notablemente los conocimientos básicos sobre las literaturas peninsulares. El docto Dieze intenta salvar el honor de los poetas españoles contra los prejuicios reinantes y "abrir a sus compatriotas un nuevo campo de la literatura, donde aún se pueden lograr importantes e inesperados descubrimientos" (prólogo, p. 3). Poco antes, con motivo de una reseña de la versión alemana de los romances de Góngora hecha por Johann Georg Jacobi (Halle, 1767), había recomendado "que tomásemos más en cuenta a los españoles tan desacreditados hasta entonces"', pero advierte al mismo tiempo las consecuencias que se seguirían en caso de que los poetas españoles se pusieran de moda ${ }^{10}$. El manual de Dieze-Velázquez se convirtió para Herder en una "Übersicht in die Seele""11 - panorama del alma del pueblo español y de España, que para él llegó a ser el país más importante de la Romania. Friedrich Bouterwek fue el que se encargó de alabar en el prólogo a la Geschichte der spanischen Poesie und Beredsamkeit (Göttingen, 1804) la proverbial confraternidad entre españoles y alemanes ("somos hermanos").

En los últimos decenios del siglo XviII los traductores se esfuerzan por inculcar al lector más conocimientos de autores y obras españoles, añadiendo a sus traducciones breves ensayos. La refutación con "Proben und Thatsachen"' de los prejuicios aún existentes respecto a la literatura española es para Bertuch la justificación de sus esfuerzos como traductor $^{12}$. Por esa misma razón, T.C. Tychsen incluye también notas "Über den gegenwärtigen Zustand der Literatur in Spanien" en un

7 Daniel Schiebeler, "Einige Nachrichten, den Zustand der spanischen Poesie betreffend", Neue Bibliothek der Schönen Wissenschaften und. Freyen Künste, 1766, t. 1, pp. 209-234.

8 Paris zündet die Lichter an. Literarische Korrespondenz, ed. K. Schnelle, München, 1977, pp. 22 s.

9 En el mismo año salió igualmente Die Thorheit von Europa, s.I., 1748.

10 Allgemeine Deutsche Bibliothek, 5 (1767), núm. 2, p. 352 s.

11 WOlfGang KaySER, Die iberische Welt im Denken J. G. Herders, Hamburg, 1945.

12 Magazin der spanischen und portugiesischen Literatur, Weimar, 1780, t. 1, pp. iv $s$. 
apéndice a la edición del libro de Jean-François de Bourgoing, Reise durch Spanien $^{13}$, que habrían de ser completadas poco después por Christian August Fischer, para formarse así una idea más justa de "un pueblo noble y de ingenio como era el español'.

En lo que se refiere a los instrumentos filológicos para el estudio del español, el siglo xviII presenta, en su totalidad, un panorama menos alentador ${ }^{14}$. Todavía a principios de siglo se publicaron dos gramáticas de la lengua castellana en latín, la de César Oudin (Köln, 1707, primero en francés, Paris, 1597) y la de Mathias Cramer (1702, $2^{\mathrm{a}}$ ed. 1711). El primer diccionario español-alemán de Ernst August Schmid no se publicó sino hasta 1795 . Entre estas dos fechas se sitúan aproximadamente una docena de pequeños manuales prácticos para enseñar y aprender la lengua española.

Las revistas se convierten a lo largo del siglo XVIII en una institución muy prestigiosa de la vida intelectual y cultural; después de 1750, sobre todo, aumenta notablemente la producción ${ }^{15}$. Los periódicos transmiten una gran cantidad de contactos literarios, aunque a veces muy diluidos, a un público burgués culto a través de reseñas (no pocas traducidas del francés), versiones, adaptaciones, noticias bibliográficas y juicios críticos. En lo que a la literatura española se refiere, falta aún un amplio análisis sistemático. Las revistas son la plataforma y los agentes eficaces para la divulgación de conocimientos sobre las literaturas y los países extranjeros. Entre las numerosas revistas traducidas se encuentra un solo título español, según el modelo del Spectator inglés, Der Denker, eine Wochenschrift (t. 1, Bremen, 1781), dirigido por aquel José Clavijo y Fajardo (1762-1767), cuyo lance amoroso con la hermana de Beaumarchais sugirió a Goethe el asunto para la tragedia Clavigo (1774).

Junto a las revistas, son los relatos de viajeros los que determinan, de manera decisiva, el horizonte intelectual del gran público. El lector alemán era el consumidor principal de los libros de viaje que iban aumentando rápidamente en la Europa del siglo XviII. A veces resulta muy difícil distinguir entre ficción y realidad, entre la imagen tradicional cuajada en obras literarias y las nociones auténticas del país. Sin embargo, los relatos de viaje fueron recomendados como remedio contra la influencia nociva de las novelas, porque "la mayoría de las novelas y espectáculos desconcierta a los lectores" 16 .

13 Reise durch Spanien, Jena, 1790, t. 2, pp. 292-344.

14 M. FranzBaCH, "Die spanische Sprache in Deutschland im 18. Jahrhundert", en Kritische Arbeiten zur Literatur- und Sozialgeschichte Spaniens, Frankreichs und Lateinamerikas, Bonn, 1975, pp. 25-41.

15 Para Francia, véase R. PAGEARD, 'L'Espagne dans le Journal Étranger (1754-1762) et la Gazette Littéraire de l'Europe (1764-1766)', RLC, 33 (1959), 376-400; Paul van TIEGHeM, L'année littéraire (1754-1790) comme intermédiaire en France des littératures étrangères, Paris, 1917 (reimpr. Genève, 1966); B. ZWlCKEL, Der europäische Nationalcharakter in den moralischen Wochenschriften des frühen 18. Jahrhunderts (tesis), Graz, 1973.

16 William E. Stewart, Die Reisebeschreibung und ihre Theorie im Deutschland des 18. Jahrhunderts, Bonn, 1978, pp. 196 ss. 
En efecto, así era el caso en lo que toca a España, y sólo más tarde se llegó a reconocer que los franceses inventaban los relatos de viaje como si fueran novelas ${ }^{17}$. La imagen de España que se está formando en Alemania se basa fundamentalmente en fuentes francesas hasta bien entrada la segunda parte del siglo (memorias, obras históricas, Voltaire, Montesquieu $)^{18}$. De ahí que esté inevitablemente desfigurada por la óptica hostil de los franceses respecto a España, que sigue haciéndose sentir cuando ya existen libros más objetivos y actualizados sobre España. Hacia mediados de siglo se empiezan a publicar relatos de viajeros ingleses sobre España, un cambio de enfoque que coincide con un mayor interés en Alemania por la literatura y filosofía inglesas (Shakespeare, Fielding y otros). Edmund Clarke, cuyas Letters concerning the Spanish Nation aparecieron en Lemgo en 1765, se lamenta en el prólogo por la general falta de información sobre España, basada sobre todo en relatos novelescos o anticuados. El influjo de los relatos de viaje sobre la comprensión y recepción de la literatura española merecería un estudio aparte. Éstos contienen cantidad de informaciones acerca de la vida literaria, representaciones teatrales, así como datos bio-bibliográficos (por ejemplo, Richard Twiss, Travels through Portugal and Spain, London, 1755, versión alemana publicada en Leipzig, 1776, con un suplemento literario; Antonio Ponz, Reise durch Spanien, Leipzig, 1775, traducción parcial del Viaje de España, con notas adicionales de Dieze).

Un aspecto importante de los relatos es la literarización del paisaje, la vivencia del paisaje español, que tiene como fondo básico tan sólo los recuerdos de lecturas de libros anteriores. John Talbot Dillon escribe, en su Reise durch Spanien (Leipzig, 1782), que es imposible viajar por España sin pensar continuamente en las escenas del Quijote; España sigue viéndose, tanto en lo positivo como en lo negativo, a través del reflejo desfigurado y desrealizado de las obras literarias. Heinrich Wilhelm von Gerstenberg ofrece, en una correspondencia fingida desde Madrid, una imagen de España en la que la visita de aquellos "glückseligen Örter" (locus amoenus), lugares que han servido de escenario a las proezas del Hidalgo de la Mancha ${ }^{19}$, desempeña un papel primordial. El lugar proporciona "a la fantasía un campo mucho más libre que las mejores instituciones en Europa".

España se presenta en cierta manera como isla de los bienaventurados. William Dalrymple opina que, para entender de verdad el Quijote, hay que visitar Castilla, pues sólo allí el pueblo es aún tan romántico

17 Ibid, p. 199.

18 W. BRÜGgEMANN, "Die Spanienberichte des 18. und 19. Jahrhunderts und ihre Bedeutung für die Formung und Wandlung des deutschen Spanienbildes", Gesammelie Aufsätze zur Kulturgeschichte Spaniens, 12 (1956), 1-146; Elena Fernández Herr, Les origines de l'Espagne romantique. Les récits de voyage 1755-1823, Paris, 1973; P. Ilie, "Exomorphism: Cultural bias and the French image of Spain from the War of Succession to the age of Voltaire", ECS, 9 (1975-1976), 373-389.

19 Briefe über Merkwürdigkeiten der Literatur (1767), Stuttgart, 1890, t. 3, p. 258 
("romantisch") como en tiempos pasados. De esta manera, va produciéndose un cambio total en la valorización sentimental de la imagen de España que no deja de tener consecuencia para la actitud positiva frente a su literatura. Giuseppe Baretti ${ }^{20}$, en sus Reisen von London nach Genua (Leipzig, 1771-1772), intentó enfrentarse de manera crítica con las imágenes trastornadas de España que los libros de viaje habían divulgado constantemente, sin ocultar, sin embargo, sus propias experiencias y observaciones negativas. La información sobre la literatura española desempeña también en Baretti un papel considerable. La traducción del Fray Gerundio, del P. Isla, hecha sobre la versión inglesa, se vale expresamente en el prólogo del juicio de Baretti, que había llamado la atención sobre esa novela satírica. Además, Baretti es importante por lo que al redescubrimiento de la España árabe se refiere. La "geografía de las provincias espirituales del resto de Europa" va perfilándose más claramente ${ }^{21}$, a pesar de la reimpresión en 1782 del famoso libro sobre España de Mme. D'Aulnoy (que data de 1691). Por el contrario, el libro de Bourgoing (publicado en alemán en Göttingen, 1789-1790, t. 3, Jena, 1800), una verdadera enciclopedia del conocimento actual sobre España, ocupa un lugar intermedio entre la invectiva de Masson (Que doit-on à l'Espagne?') y la apología de Cavanilles (Über den gegenwärtigen Zustand von Spanien, Berlin, 1785), donde alude también a la erudición contemporánea en España. El italiano Carlo Denina ${ }^{22}$, que vivió en Alemania de 1782 a 1804, emprende en 1786, con su discurso ante la Academia de Berlín, en la Prusia protestante y racionalista, el intento sensacional de defender a España contra la reprobación de su cultura por Masson, en el artículo "Espagne" de la Encyclopédie de Diderot.

La apología vehemente de Denina, para la que tal vez estaba ya preparado por la polémica ${ }^{23}$ llevada a cabo en Italia acerca de la literatura española y la defensa de España por los jesuitas exiliados, tuvo

${ }^{20}$ F. Meregalli, "Giuseppe Baretti e la letteratura spagnola", en Studi in onore di Bruno Revel, Firenze, 1965, pp. 415-422; M. Ford Bacigalupo, "An ambiguous image. English travel accounts of Spam, 1750-1787", Dieciocho, 1 (1978), 116-138, y "A modified image. English travel accounts of Spain, 1788-1808", ibid, 2 (1979), 21-42. Para la imagen de España en Inglaterra, véase IAN ROBERTSON, Los curiosos impertinentes. Viajeros ingleses por España, 1760-1855, Madrid, 1975; Patricia Shaw Fairman, España vista por los ingleses del siglo xuii, Madrid, 1981.

21 Para los estudios historiográficos hay que mencionar a JOHANN ADOLPH FRIEDRICH voN Randel, Neuere Staatskunde zon Spanien, Berlin-Stettin, 1785-1787; H. Juretschke, "Die Anfänge der modernen deutschen Historiographie über Spanien 1750-1850", en $H J V$, t. 2, pp. 867-923.

22 Luigi Sorrento, Francia e Spagna nel Settecento, battaglie e sorgenti di idee, Milano, 1928, pp. 159-282; R. Konetzke, "Zwischen Berlin und Madrid. Preussisch-spanische Verbindungen im Zeitalter des aufgeklärten Absolutismus', en Historische Forschungen und Probleme. Festschrift Peter Rassow, ed. Karl-Erich Bron, Wiesbaden, 1961, pp. 161-173.

23 M. Tietz, “'Zur Polemik um die spanische Literatur im 18. Jahrhundert, der Streit zwischen Tiraboschi, Bettinelli und Llampillas", en Stimmen der Romania. Festschrift für W. Theodor Elwert, Wiesbaden, 1980, pp. 429-449. 
gran repercusión en un ambiente impregnado fuertemente por las ideas de la Ilustración francesa con su franca orientación antiespañola ${ }^{24}$ y que - también por razones de tipo político- quería liberarse ahora del predominio francés. Este cambio no dejó de tener sus consecuencias respecto a la apreciación de la literatura española y coincide, curiosamente, con otro cambio: el que va de un extremo, el de la España negra, a otro, el de la visión fantástica, que experimenta su mayor difusión en la literatura amena trivial, al abrirse camino la información objetiva y actual tras todos los prejuicios de la Ilustración. En las Spanischen Novellen (1796) de Karl Grosse aparecen, en abundancia, hadas, esqueletos, cavernas truculentas, secuestros, cautiverios en conventos y mucha pasión amorosa, todo situado en una España imaginada. Este contemporáneo de Goethe llega incluso a decir que "no hay carácter más propenso a los cuentos de hadas y a las narraciones de fantasmas que el español ". Herder había dado la señal para ponerse en camino al país encantado ("Zauberland"), España ${ }^{25}$. Los atributos que adornarán todo lo español son: maravilloso, singular, mágico, espléndido, grandioso. España se convierte en el "Vaterland des Romantischen", el país de lo romántico por antonomasia ${ }^{26}$. El castellano, apenas conocido y eclipsado por el francés como lengua internacional, aparece ahora como una lengua casi sagrada ${ }^{27}$. La literatura española, lo mismo que la lengua, ocupa una posición intermedia entre la literatura italiana y la literatura clásica latina. Si en tiempos de la Guerra de los Treinta Años se consideraba al español "mitad judío, mitad árabe", como sospechoso respecto a la religión y de raza impura, ahora se pone de moda la glorificación incondicional de la noble morisma. Partiendo de la imagen del caballero moro de los romances, que Morhof había calificado despectivamente de "viles canciones de moros", Herder llegó a la conclusión de que los españoles eran, desde el punto de vista espiritual y cultural, "árabes ennoblecidos". Se consagró de manera consecuente al tema del Gid. Su ciclo de romances Der Cid, tan importante para la idea romántica de Fspaña, se publicó en la revista Adrastea (1803-1804) y se inspira en la traducción de la Romantische Geschichte des Cid $^{28}$, que,

24 Hay que tomar en cuenta el gran prestigio que Voltaire gozó en los círculos intelectuales alemanes; véase MANFred Komorowski, Das Spanienbild Voltaires, Frankfurt-Bern, 1976. Del Dictionnaire historique et critique de Pierre Bayle existen dos distintas traducciones alemanas (1779-1780 y 1797) que presentan la obra en forma abreviada; véase también Ingrid Schwarz, Das Spanienbild Pierre Bayles in seinem Dictionnaire historique et critique (tesina), Siegen, 1980. Juicios muy despectivos sobre España se encuentran en Jüdische Briefe oder philosophischer, historischer und kritischer Briefwechsel, Berlin, 1770-1785 (el original es de 1736) del Marqués d'Argens. p. 235.

25 Johann GotTfried Herder, Sämmtliche Werke, Stuttgart-Tübingen, 1862, t. 24 ,

26 KarL Grosse, Briefe über Spanien, Halle, 1794, t. 1, p. 9.

27 Herder, op. cit., p. 235.

28 Incluida en Neuen Teutscher Merkur, 3 (1792), núm. 1, 199-216. 
por su parte, se atiene a una versión francesa en prosa de la Bibliothèque des Romans (1783).

La España menospreciada queda ahora ennoblecida por su contacto con el genio oriental y representa incluso la cuna de una nueva cultura. El extremo Oriente y Occidente se unen en la antropología cultural de Herder: "Su país y carácter, su parentesco con los árabes, su constitución, hasta incluso su orgulloso retraso frente a la cultura europea, les convierte, por así decir, en asiáticos europeos"'29. La mezcla de elementos totalmente diferentes - romano, árabe, godo-, penetrada por el espíritu cristiano-caballeresco medieval, hace finalmente de España el país romántico y anticlasicista por definición.

El modo y las formas más genuinas de la recepción son la traducción, la parodia, la adaptación y la refundición. El siglo xvin fue una gran época para las traducciones ${ }^{30}$ del francés, del inglés, del español y del italiano. Fue también una época en que las parodias, las imitaciones ridiculizadoras y las sátiras gozaron de una gran popularidad. En cuanto al negocio de las traducciones Bertuch se atreve a afirmar: "Nosotros los alemanes siempre hemos sido como 'abejas' de las literaturas extranjeras. Ninguna nación se ha dedicado con más ahínco a estudiar las lenguas de otros pueblos que nosotros, no por pobreza en nuestras tierras, sino por curiosidad y diligente espíritu nacional" "31. Christian Heinrich Schmidt opina acerca de la traducción con una comparación menos pacífica:

Si acaso algún día los conquistadores de traductores se hicieran tributarios también de España, ciertamente, en ese momento se convertiría la hasta entonces estrecha calle para transitar las provincias del genio español en una amplia carretera, y nosotros los alemanes, como heighwaymen (!), encontraríamos material para saquear ${ }^{32}$.

Las traducciones al latín de obras españolas, que en el siglo Xvir se hacían con relativa frecuencia, se tornan escasas en el $\mathrm{xVIII}^{33}$.

Se oye a menudo la queja de que los libros españoles son difíciles de conseguir en Alemania. Como el comercio de libros con España no

29 Christian Heinrich Schmid, en Theorie der Poesie, Leipzig, 1767, t. 1, pp. 69 s., compara a los españoles con los "Chinesern".

30 Helmuth Kiesel y Paul Münch, en Gesellschaft und Literatur im 18. Jahrhundert. Voraussetzungen und Entstehung des literarischen Markts in Deutschland, München, 1977, apenas aluden a las traducciones; véase también FrIEDMAR APEL, Literarische Übersetzung, Stuttgart, 1983, pp. 41-50 y 69-77.

31 Magazin der Spanischen und Portugiesischen Literatur, Weimar, 1780, t. 1, p. iii.

32 Ibid., p. 70 .

33 Véanse mis estudios sobre "La difusión europea de la literatura española en el siglo XVII a través de traducciones neolatinas', I, 7 (1978), 3-17; y "Die lateinschsprachige Rezeption der Werke von Teresa de Jesús in Deutschland', ibid., 18 (1983), 9-21. Adam Ebert, un jurisconsulto de Frankfurt-Oder, dedicó su versión latina (1712-1718) de las obras de Gracián al Kronprinz Federico de Prusia (más tarde Federico el Grande). Además hay dos versiones neolatinas del Oráculo manual. Las obras 
funcionaba todavía libremente, un crítico anónimo de la traducción alemana del Fray Gerundio se atreve a proponer que algunos editores reimpriman en ediciones piratas, con el apoyo de las autoridades, los libros de los mejores autores españoles, para aprovechamiento del mundo literario. Bertuch, que era editor, se queja con inquietud del mal estado de los pocos libros españoles que llegan a Alemania ${ }^{34}$.

El género literario más intensamente estudiado hasta ese momento, bajo el punto de vista de la refundición y la tradición temática, es el teatro español ${ }^{35}$. Su recepción se lleva a cabo por diferentes caminos y a diferentes niveles. En los programas de compañías teatrales ambulantes se encuentran bastantes piezas de asuntos españoles o montadas según modelos españoles (en su refundición holandesa, italiana o francesa). El estudio de la comedia española del Siglo de Oro está relacionado con la discusión teórica acerca del teatro y la creación de un " $\mathrm{Na}$ tionaltheater" en Alemania.

Desde mediados del siglo xvin se presta cada vez más atención a la comedia española, tras haber iniciado Lessing el intento de acabar con la ejemplaridad exclusiva del teatro francés como norma estética. Está convencido de que nada descubre mejor el genio de un pueblo que su poesía dramática. En la Hamburgische Dramaturgie se sirve para su estudio comparativo, por vez primera, del análisis de obras de teatro españolas, además de los ejemplos franceses e ingleses, oponiendo a la fuerte rigidez de las reglas en Francia la originalidad de los españoles. Considera el desarrollo histórico del teatro español y señala las deudas del francés con éste. También Schiebeler se muestra fascinado por el nuevo mundo dramático y dice: "Ninguna nación es tan rica en obras de teatro como la española y merecen nuestra atención, ante todo, por los enredos" "36. Dieze confirma estos juicios, añadiendo: "Si los italianos y franceses restituyesen sus hurtos teatrales tanto clandestinos como manifiestos a los españoles, sería mucho lo que perderían"37.

Más que la íntima relación entre el fondo y la forma, interesaban entonces sólo la intriga dramática, los lances ("Theaterstreiche"), las invenciones y los enredos. En un anuncio de Schauspiele nach spanischen

de Antonio de Guevara se publicaron en latín, Frankfurt, 1716. L'esprit de don Antonio de Guevara, Frankfurt, 1760, contiene 400 sentencias en latín, italiano, francés y alemán, sacadas de las Epistolas (Epistolae, Viena, 1744, 1746).

34 Der Teutsche Merkur, 29 (1782), núm. 3, pp. 88 s.

35 Hermann Tiemann, Lope de Vega in Deutschland, Hamburg, 1939; Werner BrügGemann, Spanisches Theater und deutsche Romantik, Münster, 1964; Martin FranzBACH, Untersuchungen zum Theater Calderóns in der europäischen Literatur vor der Romantik, München, 1974; F. Meregalli, “L'Italia mediatrice tra il teatro spagnolo e la Germania nel Settecento", Arcadia, 13 (1978), 242-254; Henry W. Sullivan, Calderón in the German lands and the Low Countries. His reception and influence, 1654-1980, Cambridge, 1983.

36 Schiebeler, art. cit., p. 215.

37 Dieze, op. cit., p. 298. 
Plänen de Rupert Becker (Leipzig, 1783) se dice: “De tan rico material se puede escoger con juicio y conocimiento algo aprovechable para nuestros teatros". Estas piezas fácilmente podrían adaptarse a la escena alemana ${ }^{38}$. Así se pone de manifiesto la razón de que la mera traducción de obras teatrales españolas sólo ocupara un rango secundario. Más importantes son, por el contrario, los aspectos temáticos como muestran, por ejemplo, las numerosas refundiciones de Don Juan (en óperas, comedias de guiñol, ballets y dramas).

En el campo de la poesía alemana del siglo Xvir, el rasgo más sobresaliente de la recepción de la lírica española es la trayectoria formal del romance ${ }^{39}$. Johann Georg Jacobi, profesor de filosofía y retórica, tradujo los romances de Góngora con la esperanza "de gue ofrecieran nuevas ideas a nuestros poetas". Al comienzo sólo se conocía el romance artístico, entendido únicamente como Lied (canción), con un "tragicomischen Vorwurf"', después de que J.E. Ludwig Gleim hubiera intentando introducir la forma del romance, basándose en una traducción francesa de François A. Moncrif, con lo que pretendía ennoblecer el "Bänkelsang". El descubrimiento de los romances populares tradicionales se debe a las Volkslieder (canciones populares) de Herder quien, además de valerse del Cancionero de romances (Amberes, 1550, 1555, 1568) de Góngora, y de la Historia de los vandos de los Zegries y Abencerrages de Ginés Pérez de Hita, recurre, en primer lugar, a refundiciones francesas para su gran ciclo del Cid. La idea que Herder concibe de los romances como expresión de aquella originalidad poética que deja traslucir "el carácter de un pueblo, su lengua y su país. . . su música y su alma" trae consigo grandes consecuencias para la concepción de la poesía romántica. Friedrich Schlegel ve en ellos "die sinnreichste Kunst in der geistigsten Sprache”. Frente a la importancia del romancero, la poesía anacreóntica (E.M. de Villegas), recomendada también por Dieze, y las fábulas literarias de lriarte (traducidas al alemán, Leipzig, 1788), han tenido poca irradiación, a pesar de insertarse ambas en fuertes corrientes literarias similares en Alemania.

Para ilustrar tanto la continuidad como el cambio en las relaciones literarias hispano-alemanas, entre el Barroco tardío y los inicios de la Ilustración, no hay nada mejor que el ejemplo de la recepción de Gracián, cuyo desarrollo ha sido cuidadosamente estudiado por Knut Forssmann ${ }^{40}$. Considerando la época y la transformación del ambien-

38 Ibid., p. 330.

39 Sobre el romance en Alemania hay varios estudios monográficos: MARGRET Ohlischlaeger, Die spanische Romanze in Deutschland (tesis), Freiburg/Br., 1926; MarGRET STAub, Die spanische Romanze in der Dichtung der deutschen Romantik (tesis), Hamburg, 1970. Para Góngora en especial, véase WALTER PABST, Luis de Góngora im Spiegel der deutschen Dichtung und Kritik, Heildelberg, 1967; W. FALK, "Die erste deutsche Begegnung mit Góngora”, GRM, 17 (1967), 26-52.

40 Baltasar Gracián und die deutsche Literatur zwischen Barock und Aufklärung (tesis), Mainz, 1977. 
te intelectual y social de Alemania, sorprende la intensidad de la difusión de Gracián. El éxito de Guevara, basado, en lo esencial, en los elementos ascético-cortesanos y teológicos de su obras didácticas, había palidecido desde la Contrarreforma, a pesar de las reimpresiones de Opera omnia (1716), Das vergnügte Land-und beschwerliche Hof-Leben (1725-1751), así como de las Epistolas (incluso en latín 1744, 1746). En cierto modo va a ser sustituido por Gracián, como autoridad, en una época de transición de la cultura cortesana y religiosa a la cultura burguesa, laica y mundana. La transformación del homo politicus en galant homme burgués, se opera no en último término bajo el signo del jesuita Gracián. Después de haberse desarrollado en la filosofía política del siglo xvir el ideal de la discreción en asuntos de interés público-estatal, el interés se vuelve ahora con fuerza hacia la discreción privada, que dirige el comportamiento social de los individuos. Esta situación ambigua se manifiesta en que, por una parte, El político don Fernando el Católico (1640) fue reeditado en Leipzig, 1721, en la versión de Daniel Casper von Lohenstein (Staats-kluger Catholischer Ferdinand, Jena, 1672), casi 50 años desnués de su primera publicación. Se trata de un espejo de príncipes barroco que alababa claramente la monarquía de los Austrias, cuyo remado, sin embargo, había dejado entre tanto de existir en España. Por otra parte, el gran prestigio de Gracián en Alemania se basa en la versión francesa del Oráculo manual de Nicolas Amelot de la Houssaie (Paris, 1684) que lleva precisamente el título alterado L'homme de Cour. El joven filósofo y jurisconsulto, Christian Thomasius, anunció en Leipzig en 1687-1688 su famoso curso en alemán (y no en latín, que era de rigor en la Universidad) sobre Gracián bajo el título de "Grund-Reguln vernünftig klug und artig zu leben", cuya doctrina política (Politische Lehr-Sätze) consideraba apropiada para personas de cualquier estado y no tan sólo cortesanos o nobles, para que adquiriesen "eme gescheidte Conduite". El análisis detallado de la versión francesa, y del original español, está relacionado además con el Discours von Nachahmung der Franzosen (1687-1701), donde Thomasius pone en duda la superioridad y el prestigio de la cultura francesa como modelo universal. Con el tratamiento académico de Gracián quedaba trazado el rumbo de la recepción alemana posterior, que era y siguió siendo, en el fondo, asunto de los círculos eruditos; lo que también queda documentado si se tiene en cuenta que sólo del Oráculo manual hay tres versiones latinas diferentes y una versión manuscrita.

A la primera traducción alemana del Oráculo manual, de Johann Leonhard Sauter (Leipzig, 1686, $2^{a}$ ed. 1687), sigue otra del médico Christian Weissbach (seudónimo Selintes o Silentes): Homme de Cour, Oder: Kluger Hof-und Welt-Mann (Augsburg, 1711 y 1715). En Augsburgo se había publicado ya en 1710 el texto francés de Amelot. August Friedrich Müller, también profesor de filosofía de la Universidad de Leipzig, dio cursos sobre Gracián, como Thomasius, e hizo imprimir en Leipzig (1715-1719) su propia traducción, provista de un extenso 
comentario, y el texto completo en español, lo que es algo inusitado en la producción editorial alemana del siglo xviII. Al lado de una edición sin fecha del Oráculo manual, hay una segunda en 1733 con el título Oracul, Das man mit sich führen und stets bey der hand haben kan. Das ist KunstRegeln der Klugheit. La tercera traducción alemana del siglo XvIII, la de Christoph Heinrich Freiesleben, recurre a la versión italiana de Francesco Tosques (Roma, 1698) al mismo tiempo que compara las tres anteriores: Uomo Di Corte, Oder Kluger Hof-und Welt-Mann (Altenburg, 1723). Tosques a su vez manejó el texto francés de Amelot.

Con esto cesa, de momento, el entusiasmo por el Oráculo manual; sólo unos cincuenta años después, cuando la traducción de Huarte (Prüfung der Köpfe), debida a Lessing, fue reeditada y corregida por Johann Jakob Ebert, y cuando se publicó en alemán la Kritik gemeiner Irrthümer (Gotha, 1791) del Padre Feijoo, apareció otra versión con el título Die Kunst zu leben (1786, Marburg, $2^{\mathrm{a}}$ ed., 1790 y 1795), a cargo de Christian Jakob Wagenseil. Otro profesor de filosofía de Leipzig, Karl Heinrich Heydenreich, elaboró la última traducción parcial del siglo XvIII, que sería publicada en 1803 después de su muerte (Der Mann von Welt, eingeweiht in die Geheimnisse der Lebensklugheit).

Frente al éxito extraordinario del Oráculo manual tanto a principios como a finales del siglo xvIII, el Discreto permanece totalmente eclipsado. Fue vertido al alemán por un pastor luterano, el erudito Johann Jakob Brucker, siguiendo la paráfrasis francesa de Joseph de Courbeville, S.J., con el título Der Vollkommene Mensch Oder: Wahre Abbildung Eines Weisen Mannes, Augsburg, 1729.

El influjo del Oráculo manual de Gracián lo pone de manifiesto finalmente una antología de cincuenta máximas para la enseñanza de la lengua y la moral, que Johann Georg Meintel había presentado a sus alumnos en seis idiomas modernos, además del latín, junto con sentencias tomadas del Télémaque de Fénelon (La petite école de la morale et des langues, das ist: Die Kleine Sitten-und Sprachen-Schule, Nürnberg, 1732).

En la época de la novela política, en que el tema de los viajes y el desencantamiento del mundo desempeñaban un gran papel, la novela filosófico-alegórico-satírica de Gracián fue tenida en consideración, puesto que pretendía unir la aspereza de la filosofía con la amenidad de la poesía y la mordacidad de la sátira con el encanto de la epopeya. Christian Gryphius había planeado ya una traducción de la obra que, por una parte, pusiera de manifiesto lo pasajero de la vida como camino transitorio y, por la otra, lo ilustrara alegóricamente como un proceso ejemplar de desciframiento progresivo del mundo.

A la primera traducción, anónima, sigue la versión francesa de Guillaume de Maunory con el título cambiado, L'homme detrompé(Paris, 1696) y, como aquélla, sólo trae la primera parte. Las dos partes siguientes fueron traducidas al alemán por Gaspar Gottschling, que también se apoya en una redacción francesa (1705). Las tres partes se publicaron juntas en 1710 (nuevamente en 1721, con el título Der Entdeckte Selbstbe- 
trug), lo que una vez más demuestra cierta continuidad de transmisión ${ }^{41}$.

A pesar de que la narración picaresca no se había seguido desarrollando de manera original en la literatura alemana del siglo XvIII, en comparación con Francia e Inglaterra, no era desconocida en Alemania. Todo lo contrario, disfrutó sin ruptura alguna de la predilección del gran público del siglo xviII. La novela cómica trivial es el tipo opuesto a la alta novela galante, política o sentimental. Así como Johann Christoph Gottsched desterró del teatro al "miserable" gracioso, de la misma manera el loco, el pícaro, era incompatible con las normas y las convenciones del género sublime. Por eso la novela trivial aparece también sin el rótulo de "Roman" y cuenta siempre la "historia de la vida" o las "aventuras curiosas" que desenmascaran la realidad como tal, en forma satírica.

La tradición picaresca está vigorosamente presente en traducciones, tanto de novelas picarescas españolas como también de obras francesas e inglesas inspiradas en ellas, que dan un nuevo sentido a la picaresca, o la modifican. Ambas vías de transmisión refuerzan el influjo posterior de la novela picaresca de manera evidente, como lo demuestran los esquemas narrativos de las novelas de aventuras ("Robinsonaden"), las biografías y memorias burguesas.

Es extraño que, en la historia de la recepción de la novela picaresca en Alemania, no hayan sido debidamente apreciadas, hasta ahora, las numerosas y afortunadas traducciones de las obras de Lesage ${ }^{42}$. Herder había notado ya su importancia en la transmisión del género, tan popular en Francia como en Alemania. De hecho, el público lector siguió siendo fiel al autor francés, que nos había traído tantas cosas deliciosas de allende los Pirineos ${ }^{43}$. Antes, todo lo malo venía del país situado al sur de Francia, casi fuera de la Europa civilizada. España ha quedado incorporada en gran medida en Le diable boiteux, Le Bachelier de Salamanque, ou les mémoires de D. Chérubin de la Ronda tirés d'un manuscrit espagnol y en la Histoire de Gil Blas de Santillane ante todo: la geografía, la historia, el ambiente, los nombres, la descripción de los usos y costumbres dan una sensación de autenticidad ${ }^{44}$. Pero el lector extranjero no se daba cuenta de que el disfraz hispanizante aludía a la situación francesa y no a España. En una época en que la literatura de viajes ejercía gran

41 Georg Martzi (?), Balthasar Gracian Hisp. Politische Iräume Auff jetzige Zeiten Auss der Spanischen Sprach ins Hochteutsch übersetzet, Frankfurt, 1692, es probablemente una imitación satírica.

42 Son muy incompletas al respecto las referencias bibliográficas que aparecen en JOSEPH L. LAURENTI, Bibliografía de la literatura picaresca: desde sus origenes hasta el presente, Metuchen, 1973.

43 "Zur Schönen Literatur und Kunst", op. cit., t. 9, p. 348.

44 F. BRun, Strukturwandlungen des Schelmenromans. Lesage und seine spanischen Vorgänger (tesis), Bern, 1962; W. WEHLE, "Zufall und epische Integration. Wandel des Erzählmodells und Sozialisation des Schelms in der Histoire de Gil Blas de Santillane", RJ, 23 (1972), 103-129; Christian Wentzlaff-EgGebert, Beispielreihung und geschlossene Form. Studien zum Roman bei Lesage, Frankfurt, 1975. 
atracción, el Gil Blas se consideraba como un auténtico manual sobre España. Todavía a fines del siglo pasado, el viajero alemán Carl E. Geppert seguía creyendo, aun habiendo atravesado España en tren, que la mejor manera de conocer ese país era leyendo la novela francesa de Lesage $^{45}$. Pero hasta a los propios españoles les parecía la obra tan genuinamente española, que sólo podría haberla escrito un autor español. De ahí que el Padre Isla la reclamara en su reconstrucción del texto en el idioma supuestamente original (Aventuras de Gil Blas de Santillana, robadas a España, y adoptadas en Francia por M. Lesage, restituidas a su patria y a su lengua nativa por un español celoso que no sufre se burlen de su nación, 1787-1788). El escritor francés nunca había viajado por España y describe una España puramente literaria y fantasmagórica, que no corresponde en manera alguna a la realidad, sino que más bien presenta una imagen ideológica, en contraste con Francia, exóticamente distanciada, para hacer resaltar la propia intención. No es, sin embargo, la compilación de hechos geográficos e históricos y detalles de la cultura y costumbres españolas, tan notablemente parecidos a las descripciones en relatos de viaje, lo que hace del Gil Blas una obra importante para la recepción de la literatura española en Alemania. Lesage se inspira en un conocimiento magistral de toda la picaresca española y la novelística del siglo Xviı. La Histoirc de Gil Blas de Santillane no es sólo un "tableau de la vie civile", sino también una 'Summe spanischer Erzählliteratur, ja die umfangreichste derartige Summe, die es gibt" ${ }^{46}$. Ésta transmite esquemas y motivos narrativos del relato picaresco, pero en una doble refracción: a través de la adaptación francesa y la subsiguiente remodelación alemana, con todas las desviaciones producidas por la situación social y la discusión teórico-literaria.

Así como la traducción francesa del Buscón hecha por La Geneste (1633) introduce la disolución interna de la forma, que en las novelas de aventuras alemanas entre 1714 y 1754 hacía posible la unión de novela, burguesía y producción de literatura trivial, así la manera libre de Lesage en el trato con sus modelos trae consigo serias consecuencias para la nueva interpretación del "pícaro" como protagonista de una novela realista de cuño netamente burgués, que después de todo se integra como arribista de mucho mundo en la sociedad en la que vive afortunado. No en vano llegó a ser Gil Blas el libro favorito de la burguesía media. Una investigación socio-literaria tan pormenorizada como la de Dieter Reichardt sobre la transformación del Buscón en el "Aventurier" ${ }^{47}$, falta aún respecto a Lesage, la traducción de sus obras y su in-

45 Reiseeindrücke aus Spanien im Winter 1871-1872, Berlin, 1873.

46 "Suma de la narrativa española, pero la más extensa suma que existe". JÜRGEN von StackelberG, Von Rabelais bis Voltaire. Zur Geschichte des französischen Romans, München, 1970, p. 243. Dieze llegó a afirmar que: "Lesage conocía a los españoles bastante bien; sus novelas, que lo hicieron famoso, son casi una traducción del español', op. cit., p. 296.

47 Von Quevedos "Buscón”' zum deutschen "Aventurier", Bonn, 1970. 
flujo. Un estudio semejante, basado en los resultados recientes de la investigación sobre Lesage, podría informar, a través de análisis formales, acerca del desarrollo de la teoría de la traducción y la trayectoria de temas, motivos y tipos literarios, así como sobre el impacto de la novela picaresca incluso en obras triviales.

La recepción de Gil Blas fue el resultado de un malentendido, como ocurre con toda la literatura picaresca. Rötzer habla en este contexto de una "Geschichte gegen das Original" 48 . La primera traducción alemana lleva por título Der Spanische Robinson, oder Sonderbahre Geschichte des Gil Blas von Santillana (Wien, 1726, reediciones 1730,1736 y 1742). Puesto que se había iniciado ya una larga serie de imitaciones y continuaciones del Robinson Crusoe de Defoe, con títulos como Holländischer, Teutscher, Sächsischer, Französischer Robinson ${ }^{49}$, faltaba aún en la lista geográfica España, entre otras naciones. Sin más, Gil Blas fue puesto en fila directa con la moda de Robinson para aumentar su popularidad. Aunque muy diferente en cuanto a su temática y su tendencia, el Gil Blas de Lesage se comercializó junto con el raudal de robinsonadas, de la misma manera que ocurría desde 1714 con las novelas de aventuras que incorporaban al Buscón ("Buscons seltzamer Lebenslauff", en Des Spanischen Ritters Don Francisco. . . Sehr Lustige und sinnreiche Schriften, Hamburg, 1704, que además contiene "Briefe des Ritters von der Sparsamkeit" y "Die sieben Visiones oder Gesichter", todo según la versión francesa de Jean Raclots): 'La palabra 'Robinson' ha adoptado en alemán, desde hace algún tiempo, el sentido que tiene la palabra francesa 'Aventurier' "50. El género de novelas de aventuras y las novelas picarescas de baja calidad se pueden transformar fácilmente en robinsonadas, cambiando sólo la denominación del héroe. La segunda traducción de Johann Daniel Heyde (Dresden, 1768) restituye el título original, Geschichte des Gil Blas von Santillana. Entre tanto, el éxito de la novela había servido ya de incentivo a un "Lohnscribenten" anónimo (autor comercial de novelas de serie) para llevar a cabo una continuación bajo el rítulo Geschichte des Don Alphonsus von Liris, eines Sohnes des Gil Blas (Hamburg, 1744). Entre los esbozos teatrales de Lessing se encuentra el esquema de una pieza, Ludwig und Aurora, que se desarrolla en Salamanca. La protagonista femenina hace a Gil Blas su confidente.

La tercera traducción alemana, de Christhelf Mylius ${ }^{51}$, que entre otras obras tradujo también Roderick Random de Smollett, pertenece a un período (1770-1790) en que la producción y el consumo de novelas aumentaron bruscamente. Continuó editándose hasta bien entrado el

48 H. G. Rötzer, "Die Metamorphosen des Pikaro. Einige Anmerkungen zur Wirkungsgeschichte des Buscón", Daphnis, 10 (1981), 257-268.

49 Jürgen Fohrmann, Abenteuer und Bürgertum. Zur Geschichte der deutschen Robinsonaden im 18. Jahrhundert, Stuttgart, 1981.

50 Véase el prólogo a Der Sächsische Robinson oder Wilhelm Retchirs. . Wahrhaftige Beschreibung seiner. . ., Reisen, 1722-1723, ed. facs., Frankfurt, 1970.

51 Gil Blas von Santillana, Berlin, 1774, 1779-1780, 1783, 1785, 1798, 1802. 
siglo XIX. Mylius supo aprovechar lo propio del momento cuando el libro de Laurence Sterne (Sentimental journey through France and Italy, traducido al alemán en 1768) desencadenó una larga serie de novelas de viaje sentimentales y, por otra parte, la psicología experimental y la descripción de la realidad cotidiana pasaron a primer plano, de manera que el interés por la autobiografía aumentó y el relato de viajes ganó en agudeza crítico-social.

Gil Blas ofrecía en este sentido algunos aspectos adecuados y amenos. Las observaciones que Mylius recopiló señalan, además, un nuevo interés por divulgar la cultura. La novela de Lesage contiene, en efecto, uná cantidad de detalles sobre "las cosas de España", que requerían ser explicadas al gran público. De especial interés son en este sentido, por ejemplo, la exposición de Lesage sobre Góngora y el gongorismo (VII, 13) ${ }^{52}$, su entusiasmo por la poesía popular española y sus conocimientos en el campo de la comedia (el elogio de Moreto), que concuerdan con tendencias de la temprana crítica hispanística en Alemania.

La cuarta refundición alemana de la novela de Lesage lleva por título Der französische Gil Blas, oder Abenteuer Heinrich Lansons (traducido por Johann Wilhelm Heuberger, Neuwied, 1790-1791) ${ }^{53}$.

Las traducciones de la novela cómico-satírica de Lesage, Le diable boiteux, basada en la obra de Luis Vélez de Guevara El diablo cojuelo $(1641)^{54}$, son aún más numerosas en el siglo xvin que las de Gil Blas. Lesage tomó sólo algunos capítulos de su modelo español, cuyos episodios distribuyó de modo distinto, ampliándolos al mismo tiempo con elementos sacados de otras fuentes. Esta primera versión (de 1707) forma la base de las dos ediciones alemanas Der lahme Teufel (1711) y Der Hinckende Teufel des berühmten Mons. le Noble. In einem sehr angenehmen Roman, wegen seiner Curieusitäten. . . (Köln, 1711). Las traducciones siguientes se derivan de la versión considerablemente ampliada de Lesage en 1726: Der hinkende Teufel, Hamburg, 1730 (el traductor es Rudolf August Heyland) y Der lahme Teufel (traducido por Carl Heinrich Seyfried, Freiberg, 1789) y finalmente Der hinkende Teufel (traducido por Hess, Wien, 1802). Como el Gil Blas, Der hinkende Teufel ofrece materiales narrativos de origen español libremente elaborados y dispuestos. Mientras que el propio Lesage estaba menos interesado por la sátira social que por el estudio de caracteres, a la manera de La Bruyère, la presentación de esta novela en Alemania pone en un primer plano el mundo inmoral y áspero, el fondo fantástico-burlesco y la observación irónica de los aspectos aventureros de la existencia humana.

52 PABST, ap. cit., no se refiere a estos testimonios.

53 GÜNTER NigGL, Geschichte der deutschen Autobiographie im 18. Jahrhundert, Stuttgart, 1977, no considera posibles relaciones con relatos "autobiográficos" picarescos, p. 144.

54 Véase H. Will.ers, "Le diable boiteux (Le Sage) - El diablo cojuelo (Guevara). Ein Beitrag zur Geschichte der frankospanischen Literaturbeziehungen', $R F, 49$ (1935), 215-316. Uwe Holtz, Der hinkende Teufel von Guevara und Lesage. Eine literatur- und sozialkritische Studie, Wuppertal, 1970. 
También en Le Bachelier de Salamanque (1736-1738) se trata de un desarrollo ulterior de la picaresca española. El marco español es de nuevo un disfraz intencionado, pero se consideraron los episodios satíricos que contenía y la degeneración de las costumbres como un reflejo auténtico de la realidad española, que encuadra perfectamente con la imagen de España aceptada entonces. La primera traducción anónima relaciona al Bachiller con la novela cómica de estudiantes en cierta boga: Schulstaub und Hofluft, oder der glücklich gewordene Hofmeister (Leipzig, 1782) ${ }^{55}$. La segunda traducción reproduce, en parte, el título original y además sustituye las "mémoires" por "Abenteuer", colocando la novela dentro de la masa incolora de la literatura amena. Las numerosas traducciones de las tres novelas de Lesage son un aspecto parcial de la recepción del tema y fondo picaresco en Alemania, por vía indirecta a través de las refundiciones francesas.

Igualmente está relacionada con Lesage una serie de traducciones más o menos libres de famosas novelas picarescas que no sólo incorporó a sus obras, sino que él mismo había presentado en versión libre ( $L a$ valise trouvée, 1740, contiene pasajes de Marcos de Obregón de Espinel y de Castillo Solórzano). Con motivo de la refundición francesa ${ }^{56}$ de $L a$ vida i hechos de Estevanillo González, Hombre de buen humor (1746), surgieron dos versiones alemanas: Géschichte des lustigen Estevanillo Gonzalez (Hamburg, 1762) y Geschichte des Estevanille Gonzalez mit dem Zunamen des Lustigen (Wien, 1791), que se alejan del texto original por las numerosas interpretaciones episódicas sacadas de Marcos de Obregón, del Rinconete y Cortadillo cervantino y de la Vida de Gregorio Guadaña de Antonio Enríquez Gómez. También Gusmann von Alfaraches lustige Lebensgeschichte (Leipzig, 1782) se funda en la versión francesa (de Lesage) de Mateo Alemán, cuya recepción en Alemania había dejado una huella notable desde el siglo XVII ${ }^{57}$.

Una traducción anterior, de Friedrich Wilhelm Beer, Lustige Lebensgeschichte Gussmanns von Alfarache, andern zum Beyspiel von ihm selbst beschrieben und ihres besonderen Inhalts wegen ins Deutsche übersetzt (Leipzig, 1751-1752) - con la continuación apócrifa-, fue reseñada en 1751 dos veces por Lessing, quien consideró la obra como una imitación del Lazarillo de Tormes. Más importantes para la comprensión de la obra son las observaciones de Lessing sobre la traducción, por la que se perdieron, según él, "las innumerables bellezas del original, ya que el autor francés, Sé-

55 Ludwig FERTIG, Die Hofmeister. Ein Beitrag zur Geschichte des Lehrerstandes und der bürgerlichen Intelligenz, Stuttgart, 1979.

56 AleXandre CIORANeSCU, Le masque et le visage. Du baroque espagnol au classicisme français, Genève, 1983. pp. 514 ss.; E. R. MOORE, "Estebanillo González, travels in southern Europe", $H R, 8$ (1940), 24-45.

57 Hans-Gerd Rötzer, Picaro-Landtstörtzer-Simplicius. Studien zum niederen Roman in Spanien und Deutschland, Darmstadt, 1972, pp. 55 127; Marquis de Granges DE SurGÈrES, Les traductions fraņ̧aises de "Guzman d'Alfarache", Paris, 1895; R. Greifelt, "Die Übersetzungen des spanischen Schelmenromans in Frankreich im 17. Jahrhundert", $R F, 50$ (1936), 51-84. 
bastien Brémond, las ha adaptado muy al gusto francés" ${ }^{58}$. Lessing acierta en observar la pérdida sustancial que las diferentes traducciones de Lesage llevan consigo. Del análisis de Lessing merecen tenerse aún en consideración dos puntos notables. Por una parte, echa de menos el que no se haya tomado como punto de referencia una traducción italiana, más próxima al original español, sobre todo en vista de que no era raro que existiera alguna en bibliotecas alemanas. Por otro lado, es de notar la clasificación genérica de esa obra tan bien lograda en lo que toca a la "invención moral y sátira". Se trata, según su juicio, de la "biografía de un mendigo, que el autor español había elegido para describir una serie de sucesos de la vida más baja, donde los cambios de fortuna suelen ser manifiestos y sensibles"'.

En la cima de la popularidad de las novelas picarescas se mantiene el Lazarillo con siete versiones alemanas publicadas en el siglo XVIII, que se suman a otras tantas del siglo XVII. Gozan ahora, igualmente a través de versiones francesas, de nuevas simpatías. La relación exacta de las diferentes ediciones alemanas con sus modelos franceses ${ }^{59}$ y la posible repercusión de las traducciones alemanas más antiguas deberán someterse todavía a un estudio más profundo. Aquí sólo podemos señalar la presencia masiva de la primera novela picaresca, cuya popularidad ha contribuido a que estas novelas satíricas se considerasen durante mucho tiempo como la quintaesencia de la literatura española.

Das Leben Lazarillo von Tormes (traducido por P.F. Hahns, Leipzig, 1701) abre la serie de los Lazarillos alemanes del siglo XviIr. La segunda traducción (1709), según la Histoire facétieuse du fameux drille Lazarille de Tormes (1697) ofrece, con su título, algunos indicios para captar la manera de interpretar la picaresca y el modo de recepción de este género: Curieuses und Lesens-würdiges Leben Eines der Grösten doch Klügsten Narren in der gantzen Welt. Denen klugen Narren aber zum Ruhm. El pícaro, visto por Aegidius Albertinus como un peregrino hacia Dios, queda incoporado aquí dentro del desfile de bufones que con el libro de Christian Weise Die Drey ärgsten Ertz-Narren in der gantzen Welt, auss vielen närrischen Begebenheiten hervorgesucht (1672), y junto con las "Simpliziaden"' gozó de gran éxito en las postrimerías del siglo XVII (frente a la novela política didáctico-cortesana $)^{60}$. Puesto que un viaje a España y Portugal

58 G. E. Lessing, Sämtliche Schriften, Stuttgart, 1889, t. 4, pp. 266-269 y 360 (reimpr. Berlin, 1968).

${ }^{59}$ Rötzer, op. cit., pp. 1-54. Para Francia, véase Cioranescu, op. cit., pp. 491 494; E.R. Sins, "Four seventeenth century translations of Lazarille de Tormes", HR, 5 (1937), 316-332; G. LAPLANE, "Les anciennes traductions françaises du Lazarille de Tormes", en Hommage à Emest Martinenche, Paris, 1938, pp. 143-155; M. Lambert, "L'image de l'Espagne en France à la fin du XVI siècle et au XVII siècle à travers les éditions françaises de Lazarille de Tormes", Bulletin de la Bibliothéque Nationale, 5 (1980), 70-79 y 134-136; y "Les diverses continuations de Lazarille de Tormes en France", Revue Française d'Histoire du Livre, 49 (1980), 623-656.

60 Sobre los prudentes y los necios en la novela política, véase Rolf Grimminger, en Hansers Sozialgeschichte der deutschen Literatur, München, 1980, t. 3, pp. 648 ss. 
tampoco les aseguraba a los archibufones (Erznarren) a quién correspondería la corona de la locura, se ofrecía muy naturalmente una continuación con el Lazarillo y con estructuras episódicas parecidas, especialmente porque se daba lugar a la descripción del mundo humilde del tercer estado. Como ocurría con tanta frecuencia a finales del siglo XvIII, se solicita la "curiosidad" como motivación del lector que se regocija por aquellas "cosas nuevas, inauditas e inesperadas" 61 .

Frente al aventurero pícaro y al bufón está la discreción práctica, que se desenvuelve paralelamente en la literatura erudita, sobre todo, mediante la difusión de Gracián. Si las locuras son las vicisitudes de la fortuna, la discreción enseña, por el contrario, cómo se consigue la felicidad con la ayuda del comportamiento moral. Con la adopción del Lazarillo, visto con ojos franceses, lo burlesco pasa parcialmente a primer plano (la "histoire facétieuse" con tanto arraigo en la tradición cuentística popular). Las convenciones del género de la novela popular se imponen con el tipo de protagonista pícaro. La recepción en Alemania de las refundiciones que Lesage elaboró sobre la temática picaresca se produce, curiosamente, sólo hacia finales del siglo xviII. En primer lugar se sobrepuso el éxito de Gil Blas al interés de otras obras pertinentes.

Así pues, sólo en 1724 aparece una nueva edición de la novela ejemplar de Cervantes, Rinconete y Cortadillo (en la deliciosa traducción libre Isaac Winkelfeld und Jobst von der Schneidt), así como de La garduña de Sevilla, de Alonso del Castillo Solórzano (Leben und seltsame Begebenheiten der Dona Rufine, einer beruffenen spanischen Courtisane, Frankfurt-Leipzig, 1732, más tarde en Viena, 1791).

Es curiosa la tercera traducción alemana del Lazarillo (por Ludwig Carl Schnering, Rostock, Neubrandenburg, 1741 ${ }^{62}$ para conocer los caminos por donde se ha filtrado la picaresca. El traductor lo convierte en libro de texto para aprender el francés, desnaturalizando, claro está, el original. El maestro de escuela se atrevió, no obstante, a presentar a sus alumnos una lectura divertida y poco habitual para hacer más variados los aburridos ejercicios gramaticales.

La cuarta traducción del Lazarillo presenta un "texto purgado de cosas indecentes y arreglado para el pasatiempo inocente": Lustige Begebenheiten des berühmten Spaniers Lazarillo von Tormes (Ulm, 1769).

La quinta versión se atiene a un modelo francés (Abentheuer, Ungemach, Launen und Busse Lazarillos, von Tormes, Leipzig, 1782). La sexta presenta ai Lazarillo como obra de Hurtado de Mendoza e incluye la continuación de Juan de Luna. Tras otra edición, Leben des Lazarillo von Tormes (Zittau, 1794), afirmaba Carl August Freiherr von Soden haber

61 Ibid., t. 3, pp. 222 s.

62 Vie et aventures de Lazarille de Tormes Das ist, Leben und wunderbare Begebenheiten. Lazarchen (!) von Tormes eines gebohrenen Spaniers, Nebst denen darinnen befindlichen und andern deselben ähnlich oder wiedriglautenden eintzelen Wörtern, gantzen Redens. Arthen Constructionibus und Idiotismis wie auch Kurtzen Vorbericht von den Participes und Gerondifs der Frantzösischen Sprache. 
sido el primero en traducir Das Leben eines leonischen Bettlers, von ihm selbst beschrieben directamente del original (Leipzig, 1802).

En la segunda mitad del siglo xvIII, se une a la rica tradición de narraciones picarescas el influjo de tres autores relacionados con el género: Paul Scarron, Tobias Smollett y Francisco de Quevedo. En el Roman comique de Scarron (1651-1657, vertido al alemán con el mismo título, Comischer Roman, Hamburg, 1752-1753) ${ }^{63}$ están intercalados cuatro relatos - tres de Castillo Solórzano y uno de María de Zayas Sotomayor- que Scarron, gran conocedor de Cervantes y la novela corta española, tradujo libremente, modificando también la disposición del original.

Casi al mismo tiempo que la novela de Scarron (publicada hacía ya más de cien años), se tradujo en 1755 Die Abenteuer Roderick Randoms, de Tobias Smollett ${ }^{64}$, quien invocaba expresamente al Gil Blas como modelo. En esta línea cabe mencionar también a John Bunyan, The life and death of Mr. Badman, 1680 (traducido bajo el título $M r$. Quasts Leben und Sterben oder Eines Gottlosen Reise nach dem ewigen Verderben, Hamburg, 1685, 1767). Empezó la corriente con el Jan Perus, publicado en 1672, un año después de la traducción alemana del Buscón, y que es el Meriton Latroon de Richard Head, que también se apoyó en La Geneste ${ }^{65}$.

La tríada de novelas picarescas españolas está compuesta, como es sabido, por el Lazarillo, el Guzmán de Alfarache y el Buscón de Quevedo. Dieter Reichardt ha señalado la trayectoria del "príncipe de la vida buscona" en la formación de la novela de aventuras alemana. La primera versión alemana del Buscón data de 1671 , y se presenta igual que el $\mathrm{La}$ zarillo, como "histoire facétieuse". Las Sehr lustigen und sinnreichen Schriften utilizan la traducción de La Geneste ${ }^{66}$, modernizada por Jean Raclots, sin tener en cuenta el original español. Contienen no sólo "Buscons seltzamen Lebens-Lauff"' ("Der Waghalss Buscon. Eine überaus lustige Historie"), las "Briefe des Ritters von der Sparsamkeit" y las "Sieben Visiones oder Gesichter Quevedos"'67, sino también el "Nacht-Schwär-

63 Raymond CADOREL, Scarron et la nouvelle espagnole dans le "Roman comique", Aixen-Provence, 1960; Frederick AlFred DE ARMAS, The four interpolate stories in the "Roman comique", their sources and unifying function, Chapel Hill, 1971; CIORANESCU, op. cit.

${ }^{64}$ G.S. Rousseau, "Smollett and the form of Picaresque literature", en $T$. Smollett. Essay of two decades, Edinburgh, 1982, pp. 55-79; ReGine Rosenthal, Die Erben des "Lazarillo"'. Identitätsfrage und Schlusslösung im pikaresken Roman, Frankfurt-Bern, 1983.

${ }^{65}$ H.G. Rötzer, "The English Rogue in Deutschland", Argenis, 2 (1978), 229-247

66 Andreas Stoll, en Scarron als Übersetzer Quevedos, Studien zur Rezeption des pikaresken Romans "El Buscón" in Frankreich, Frankfurt, 1970, defiende la autoría de Scarron.

${ }^{67}$ Der träumende Satyr, Augsburg, 1762, es probablemente imitación de los Sueños. Así como Schnering utilizó el Lazarillo en la clase, el profesor de idiomas Giovanni Antonio Pazzaglia, un italiano residente en Hannover, preparó una selección de las Visiones en italiano para el uso en clase: Scelta della visioni. . ., s.l., 1704, $2^{\text {a }}$ ed., Augsburgo, 1706. Palau registra en su Manual del librero una edición Reisen in die Andere Welt. Lustige und sinnreiche Schriften, Kopenhagen, 1704. 
mer", sin mencionar al verdadero autor, Alonso de Salas Barbadillo (Don Diego de noche). Como es de suponer, retoma también una edición francesa (Le coureur de nuict ou les neufs aventures du chevalier dom Diego, Paris, 1631). De la misma manera que el "Nacht-Schwärmer"' se puede clasificar dentro de la tipología de un mundo inmoral, burlesco-fantástico de los locos, cuyas vidas confusas y extravagantes son satirizadas por la baja novela, así el Buscón es interpretado durante el período del "Sturm und Drang"' como Geschichte eines Kraftgenies (Hamburg, 1789)

La tercera traducción del siglo XviI la incluyó Friedrich Justin Bertuch, en el Magazin der spanischen und portugiesischen Literatur, Weimar, 1780, con el título Geschichte des Gran Tacaño Oder Leben und Thaten des Erzschalks. El primer tomo contiene además Briefe des Ritters von Spargut y Traum vom Jüngsten Gericht. Los Sueños fueron publicados en una nueva versión, cuyo título, Reisen in die andere Welt. Oder über-und unterirdische Visionen und Phantasien verschiedener Geisterseher (Leipzig, 1787) ${ }^{69}$, hace clara alusión a las entonces populares utopías de viaje con carácter satírico o a las historias de fantasmas (coloquios infernales) que hablan desde un más allá caricaturesco.

Comparadas con el importante surtido de obras picarescas, otras formas en prosa están escasamente representadas. Pero sigue siendo considerable, también en este aspecto, la transmisión a través de Francia, como lo muestra el ejemplo de Jean Pierre Claris de Florian (1755-1784), que se había servido de la primera novela cervantina, La Galatea, para refundirla casi doscientos años después de su publicación (Galatée, pastorale imitée de Gervantes, 1783$)^{70}$. Reduce a tres los seis libros del original y lleva a un feliz desenlace la obra que su propio autor dejó inacabada. En el cuarto libro se describe la magnífica boda de Galatea. La refundición tuvo mucho más éxito que la creación juvenil de Cervantes. Friedrich Melchior Grimm informaba acto seguido desde París de la novela pastoril del "admirable autor del Quijote, cuyo genio hizo famosa a España, deleitó a toda Europa y enmendó aquel siglo"71. Mylius se apresuró a dar en Berlín, en 1787, una traducción, Galathee, ein Schäferroman nach dem Cervantes, cuando andaba en boca de todos los enterados la disputa académica sobre la cuestión ¿Qué se debe a España? El libro curiosamente incluye el "Versuch einer pragmatischen Geschichte der Schäfereien in Spanien"' (Leipzig, 1785) redactado por Georg Stumpf.

68 Ésta parece ser también la interpretación que adopta Christian August Fischer cuando traduce La vida del gran tacaño por Abentheuer und Streiche eines spanischen Kniff- und Pfiff-Genies y el Guzmán como Geständnis eines Weltkindes, Leipzig, 1801-1802.

69 Herta Brögelmann, Die französischen Bearbeitungen der "Sueños" des D. Francisco de Quevedo von 1632 bis 1759. Spanische Satire im Spiegel französischen Geistes (tesis), Göttingen, 1959 .

${ }^{70}$ F. Rühfel, Florians Bearbeitung der "Galatea" des Cervantes (tesis), München, 1928; W. Schwenke, Florians Beziehungen zur deutschen Literatur, Leipzig, 1908.

71 Melchior Grimm, Paris zündet die Lichter an. Literarische Korrespondenz, Kurt Schnelle (ed.), München, 1977, p. 446. 
Otra novela pastoril, Estelle (1786-1787), la consideraba Florian como la cima de su creación artística en el género, imitando los Siete libros de la Diana de Montemayor. También esta obra, que no es más que una "edificante novela de terruño" "72, fue traducida prontamente por Karl Wilhelm Franz (Estelle, Schäferroman, Gera, 1789).

Además de la novela pastoril, ya algo pasada de moda en tiempos prerrevolucionarios, Florian aportó su contribución a la novela morisca, extraordinariamente popular en Francia desde el siglo xvII. El tema queda por investigar en la literatura alemana (exceptuando los romances granadinos $)^{73}$.

La historia árabe cobró gran interés en Alemania a partir de Herder, con el descubrimiento de la cultura mora. La España árabe, la vuelta a la época heroica de la Reconquista, la toma de Granada son temas que se emplean hasta en la literatura romántica. La nueva maurofilia se anuncia en traducciones de Gonzalo von Cordova oder die Wiedereroberung von Granada (Berlin, 1793) - novela de Florian-o de Zayde de Mme. de Lafayette (Braunschweig, 1790), cuyo original se publicó en 1670-1671. A mediados del siglo, Johann Elias Schlegel había tratado los conflictos entre moros y cristianos en el drama Die Braut in Trauer. En Nuremberg salió, en 1750, la novela de Georges Scudéry Almahide, oder Geschichte des königlichen Hofes zu Granada.

La recepción de Cervantes en Alemania durante el siglo XviII es la mejor estudiada hasta ahora, lo que ha contribuido, en parte, a que la idea del influjo español se haya concentrado en su obra ${ }^{74}$. Las traducciones del Quijote son más bien escasas si se tiene en cuenta su enorme prestigio durante la Ilustración. Dieze afirmó tajantemente que "ninguna traducción llega a igualar el original" y asimismo: "Quien quiera conocer todas las bellezas del Quijote, tiene que leerlo en español, ya que su lengua es un modelo clásico"'75.

Las referencias anteriores al Quijote son más bien vagas o desacertadas (por ejemplo, Der Spanische Waghalss: Oder des von Lieb bezauberten Ritters Don Quixott von Quixada Gantz Neue Ausschweiffung auf seiner Weissen Rosinanta, Nürenberg, 1696; el título recuerda al Wag-Halss Buscon). La primera traducción del siglo XVIII salió en 1734 en Leipzig, junto con la continuación de Avellaneda (reeditada en 1754,1767) y según

72 W. ENGler, "Jean Pierre Claris de Florian, Estelle, roman pastoral (1787)", ZFSL, 78 (1968), 302-316.

73 J. Cazenave, "Le roman hispano-mauresque en France", RLC, 5 (1925), 594-641: Marjorie Chaplyn, Le roman mauresque en France, Paris, 1928; Daniel BODMER, Die granadinischen Romanzen in der europäischen Literatur, Zürich, 1955.

74 T.W. Berger, Don Quixote in Deutschland und sein Einfluss auf den deutschen Roman 1613-1800 (tesis), Heidelberg, 1908; F. MER EGALLI, "Profilo storico della critica cervantina nel Settecento", en Rappresentazione artistica e rappresentazione scientifica nel Secolo dei Lumi, Firenze, 1971, pp. 181-210; Werner BrügGEMAnn, Cervantes und die Figur des Don Quijote in Kunstanschauung und Dichtung der deutschen Romantik, Münster, 1958.

75 Dieze, op. cit., p. 325. 
una versión francesa poco lograda de 1677-1679. Fue Bertuch el primero en traducirlo al alemán directamente del español sirviéndose, como indica con orgullo, de otras traducciones de la obra maestra (Leben und Thaten des weisen Junckers Don Quixote von la Mancha, 1775-1777, que se reimprimió en 1780-1781 con los grabados de Daniel Chodowiecki, 1798 $)^{76}$. Para la segunda parte de Avellaneda recurre a Lesage. Más que reproducir lo típicamente español, Bertuch intenta implantar la obra en un ambiente algo germanizado, con pocas supresiones, y altera a veces el orden de los capítulos.

Pasando por una versión francesa, llega igualmente a Alemania la "historia nórdica" Persilus und Sigismunda (Ludwigsburg, 1746) bajo una forma abreviada. Julius von Soden trabajó sobre el original español para traducir las Abentheuer des Persiles und der Sigismunde (Ansbach, 1782), pero las "aventuras" del título ya indican cómo entendió el sentido de la obra. A Soden le debemos también la primera versión completa de las Moralische Novellen (1779). Friedrich Johann Butenschoen fue el autor de la tercera versión del Persiles, Leyden zweyer edlen Liebenden- (Heidelberg, 1789), que incluye otra vez un ensayo histórico sobre la poesía española.

El gran prestigio de Don Quijote se debe menos a las traducciones alemanas o al influjo del original que a los juicios de eruditos y críticos, por un lado, y, por otro, a las transformaciones literarias que había causado esta novela en el resto de Europa y que, a su vez, ejercieron su influencia sobre Alemania, perceptible en numerosas traducciones y adaptaciones. A esto se une la vena satírica en la literatura de la Ilustración.

Daniel Schiebeler resume un juicio muy positivo sobre el Quijote, cuando constata que es evidente que esta obra producía un gran efecto entre los españoles restableciendo su imaginación viciada ${ }^{77}$. De tal aprecio resultan algunos aspectos importantes para la futura interpretación del Quijote, que tradicionalmente se presentó como sátira de la nobleza, la nación y la literatura españolas. La novela era considerada como espejo de todas las locuras que se le habían atribuido al carácter español dentro de la tipología tradicional de las naciones. Ya tempranamente se establece una relación rica en consecuencias entre la obra literaria y la esencia de lo español. La ficción literaria se comprende como expresión de la realidad española e impide ver, de esa manera, las cosas de España tales como son. Heinrich Wilhelm von Gerstenberg concibió el Quijote como "attische Satire" e intentó sacar conclusiones, tanto acerca de la historia como del ser de los españoles. En su entusiasmo se imaginaba, incluso, una fusión del espíritu románico con el germánico, de Shakespeare y Cervantes, como idea del super-poeta. Las

76 Berta Kronacher, Bertuchs Don Quijote- Ubersetzung. . . (tesis), München, 1923 Martin Wolf, Avellanedas Don Quijote, sein Verhältnis zu Cervantes und seine Bearbeitung durch Lesage (tesis), Leipzig, 1907.

77 Véase SchiebeIer, art. cit., p. 232. 
mismas ideas racistas pueden conducir, un siglo más tarde, a desprestigiar otra vez la literatura española en Julius Leopold Klein, cuando opone al "drama del espíritu céltico-latino, arábigo-visigótico" de los españoles (sobre todo de Calderón) el drama de un espíritu nacional vigoroso de "más pura mezcla germánica y más profunda idealidad" (de los ingleses, Shakespeare).

Herder llevó a cabo un cambio cualitativo en la interpretación prerromántica del Quijote visto como espejo del carácter nacional. Le parece un "unvergleichlicher National-Roman" (1784). Junto con los romances representa un "Gewächs der spanischen Sprache und Denkart" (nótese la imagen biológica y orgánica). Así pues, Cervantes ya no aparece en primer lugar como escritor satírico, sino como poeta nacional, cuya obra es expresión del alma popular y forma la literatura nacional. Por consiguiente, la imagen de España adquiere un matiz totalmente nuevo: "Los enredos y aventuras que llenan las novelas españolas convierten, en nuestra fantasía, el hermoso desierto y el campo tras las montañas en un país mágico"'78.

Tomando como ejemplo el Quijote, se pueden explicar la parodia y la "travestie" como formas de recepción por excelencia. La condición para el nacimiento y éxito de la parodia es precisamente la existencia de una obra literaria famosa, a la que se refieren con sus recursos, alusiones y caricaturas. Se presupone que el lector está bien familiarizado con el modelo, para poder comprender los efectos ingeniosos y sutiles de la parodia. Hay una serie de obras con carácter paródico que documentan la intensa repercusión del Quijote en la creación literaria del setecientos.

Ya en óperas bufas francesas y alemanas aparece el personaje del Caballero de la Triste Figura de manera episódica, incluso hasta principios del siglo XviII. En lo que a la parodia en la novela alemana de la Ilustración se refiere, el mejor ejemplo es Der Teutsche Don Quichotte, oder die Begebenheiten des Marggrafen von Bellamonte. Komisch und satyrisch beschrieben (Breslau, 1753) ${ }^{79}$. El protagonista es el hijo joven y ocioso de un comerciante, que confunde el mundo fantástico de las novelas galantes francesas con la realidad, un tema muy actual debido al enorme auge de la lectura (producción de libros, difusión de revistas, pedagogía, círculos de lectores y bibliotecas públicas). Acompañado por su criado, va en busca de aventuras amorosas y, finalmente, comprende que hay gran diferencia entre la ficción ideal y la realidad cotidiana de sus experiencias.

También a don Sylvio, en Der Sieg der Natur über die Schwärmerey oder die Abentheuer des Don Sylvio von Rosalva (Ulm, 1764) de Christoph Mar-

78 Sämmtliche Werke, Stuttgart-Tübingen, 1862, t. 9, p. 348.

79 L. Kurth y H. Jantz (eds.), Berlin, 1972. Algunos ejemplos más tempranos: Heinrich Hintz, Der irrende Don Quixote, Ritter de la Mancia, Hamburg, 1690; Die Verliebte Verzweiflung, in einem anmuthigen spanischen Roman nebst ganz neuen Abentheuern des Ritters Don Quixote, trad. del francés, Leipzig, 1718. 
tin Wieland, llega a trastornársele el juicio, a causa de la lectura de cuentos de hadas franceses, y sale en busca de su hada. La historia interpolada en la novela "Geschichte des Prinzen Biribinker", una desfiguración grotesca de los "contes de fées", cura a don Sylvio como un remedio homeopático de su ilusión disparatada y lo devuelve al mundo real. Se casa con doña Felicia, que se transforma felizmente en un personaje real, dejando de ser mera ficción.

Entre el Teutschen Don Quichotte y Don Sylvio de Rosalva se sitúan dos parodias tomadas de la literatura extranjera: Don Quixote im Reifenrocke, oder die abentheuerlichen Begebenheiten der Romanheldin Arabella (Hamburg, 1754) de Charlotte Lennox y Sancho Pansa, Geschichte des vormahligen Stallmeisters von Don Quixote (Leipzig, 1754, traducido del francés). La figura de Sancho ha inspirado continuaciones de carácter paródico ${ }^{80}$.

A partir de los años sesenta, el influjo del Quijote se intensifica a través de numerosas traducciones de obras inglesas que, a su vez, siguen declaradamente la obra cervantina; por ejemplo, de Henry Fielding, Joseph Andrews, "written in imitation of the manner of Cervantes"' (1742), traducido en 1765 con el título Komischer Roman; Tom Jones. Hudibras de Samuel Butler atrajo a tres traductores entre 1765 y 1787. Johann Gottfried Gellius presentó en alemán The spiritual Quixote, or, the summers ramble of Mr. Geoffry Wildgoose (London, 1773; Der geistliche Don Quixote, Leipzig, 1775). Por aquellos años en que Bertuch trabajaba en la traducción del Quijote, se intensificó de nuevo el interés por la sátira; mencionamos tan sólo a título de ejemplo a Johann Carl Wezel, Lebensgeschichte Tobias Knauts des Weisen, 1773-1776; Johann Gottwerth Müller, llamado Itzehoe, Siegfried von Lindenberg, 1779 y Theodor Gottfried Hippel, Kreuz- und Querzüge des Ritters von A biz Z, 1793-1794.

La recepción del Quijote tuvo lugar incluso en el campo de la "literatura infantil", que a fines del siglo xvir recibió un gran impulso debido a las adaptaciones para jóvenes de libros destinados, en principio, para adultos (piénsese en Robinson Crusoe, adaptado con éxito fulminante por Johann Heinrich Campe y Johann W. Wezel). El prólogo al Quijote (Leipzig, $3^{\mathrm{a}}$ ed., 1767) destaca precisamente que se presta como lectura para jóvenes (después de tantas advertencias en el siglo anterior de que era una obra peligrosa). Christian Karl André arregló Leben und Thaten des weisen Junkers Don Quixote von Mancha para la serie "Lustige Kinderbibliothek' (Marburg, 1787-1789) ${ }^{81}$.

80 Tal como Antons Pansa von Mancha fortgesetzte Abhandlungen von Sprüchwörtern, Leipzig-Frankfurt, 1777; R.M. FLORES, Sancho Panza through three hundred seventy-five years of continuations, imitations, and criticism, 1605-1980, Newark, 1982, no registra ningún título alemán de la época que nos interesa. Véase además Rolphard Steimer, Erscheinung und Bekehrung des Don Quixotte de la Mancha, im letzten Viertel des achtzehnten Jahrhunderts, Wesel, 1786; A.V. GöCHHAusen, Freymaurerische Wanderungen des weisen Junkers Don Quixote von Mancha und des grossen Schildknappen Herrn Sancho Pansa, Eine Jahrmarktposse, 1787.

81 Theodor Brüggemann y Hans-Heino Ewers, Handbuch zur Kinder- und Jugend- 
Carl Friedrich Flógel resume en el cap. XII de su Geschichte der komischen Literatur (Liegnitz, 1785) la opinión común del siglo XVIII sobre el Quijote. Raras veces pueden determinarse con tanta claridad los límites de una época y los cambios de paradigma, como en el caso del romanticismo alemán que, entre 1797 y 1805, logró operar una transmutación total de las ideas hasta entonces existentes, consagrada por dos nuevas traducciones del Quijote: la de Ludwig Tieck y la de Soltau ${ }^{82}$.

Si para concluir echamos una mirada retrospectiva a los contactos literarios hispano-alemanes en el curso del siglo XVIII, éstos no son, por lo menos con respecto a la literatura profana, de menor intensidad que durante el Barroco. Christian Gryphius no había previsto tan equivocadamente el curso de los hechos, cuando en su obra Der deutschen Sprache unterschiedenen Alter ${ }^{33}$, de manera alegórica, pone en boca de España el consejo a Alemania de que en el futuro se oriente en Quevedo, Gracián, Saavedra (probablemente, Cervantes), Hurtado de Mendoza (supuesto autor del Lazarillo), Alemán y Úbeda para que no falte "diversión lícita y singularmente culta". Gracián, la picaresca y Don Quijote representan sólo una parte del balance; la lírica y el teatro están igualmente presentes. Aunque España había desaparecido del todo del horizonte político europeo, después de la Guerra de Sucesión, y predominaban la lengua, la literatura y las formas de vida francesas, se siguió prestando atención a las letras españolas con interés creciente, a pesar del peso abrumador de la mala prensa que tenía España y que reforzaban, en buena parte, autores franceses. El modelo español ejerce una atracción cada vez más poderosa en los intentos de fundamentar una "literatura nacional", un "teatro nacional" y una "novela nacional" en la Alemania del siglo xviri. El camino que había de llevar a la exuberancia, al delirio de los románticos ante lo español, fue marcado ya hacía tiempo, en el siglo XVIII*.

DIETRICH BRIESEMEISTER

literatur von 1750-1800, Stuttgart, 1982, pp. 338-348; H.H. EwERs, "Der Don Quijote als Jugendlektüre im 18. Jahrhundert”, Die Schiefertafel, 3 (1980), 3-29.

82 Anthony Ciose, The romantic approach to Don Quijote. A critical history of the romantic tradition in Quixote criticism, Cambridge, 1978; F. Meregalli, "Cervantes nella critica romantica tedesca"', $A C F o, 11$ (1972), 381-395.

83 Christian Gryphius, Der deutschen Sprache unterschiedenen Alter, Breslau, 1708 , p. 165 .

* Agradezco al Sr. Nicolás Rivero Salavert la traducción del presente artículo. 